\title{
A prática da educação física para idosos ancorada na pedagogia freireana: reflexões sobre uma experiência dialógica-problematizadora
}

\author{
Mesaque Silva Correia* \\ Maria Luiza de Jesus Miranda** \\ Marília Velardi ${ }^{* * *}$
}

\begin{abstract}
Resumo: O pensamento pedagógico freireano tem favorecido significativamente a ampliação de práticas educativas formais e não formais e contribuído com a ampliação de leituras críticas de mundo no qual os educadores têm buscado em suas categorias de análises amparo para suas inquietudes. Desta forma, partindo das leituras do legado freireano o objetivo do presente estudo é refletir criticamente sobre as categorias diálogo e autonomia, assim como iniciar discussões a respeito da prática da educação física para idosos ancorada nos pressupostos teóricos da pedagogia freireana. Para tanto, refletiremos sobre uma experiência dialógicaproblematizadora.
\end{abstract}

Palavras chave: Educação Física. Idoso. Autonomia pessoal.

\section{INTRODUÇÃO}

Nas últimas décadas, o mundo tem voltado a atenção para o crescimento a passos largos da população idosa. O envelhecimento populacional, um fenômeno que é recente, tem originado estudos de diferentes áreas como: Filosofia, Sociologia, Antropologia, Gerontologia, Psicologia, Economia, Saúde Pública, Educação Física entre outras. Alguns desses estudos têm buscado evidenciar que o envelhecimento é um processo natural pelo qual os seres vivos passam, mas a velhice é uma categoria histórica e socialmente construída, produzida pela modernidade oprimida pela dependência social e opressora pela falta de socialização do poder.

\footnotetext{
"Projeto Sênior para a Vida Ativa. Universidade São Judas Tadeu (USJT). São Paulo, São Paulo, Brasil. E-mail: mesaquecorreia@bol.com.br

**Doutora em Psicologia pela Universidade de São Paulo. Professora da Universidade São Judas Tadeu. Coordenadora do Projeto Sênior Para a Vida Ativa e do Grupo de Estudo e Pesquisa Sênior.

***Doutora em Educação Física pela Universidade Estadual de Campinas. Professora da Universidade de São Paulo. Coordenadora do Grupo de Estudo e Pesquisa Sênior.
} 
Nas relações estabelecidas entre o indivíduo velho e os demais membros da sociedade, é perceptível em qualquer classe social uma visão estereotipada do idoso. Visão na maioria das vezes carregada de distanciamento e indiferença, na qual o imaginário social percebe o ser velho como um sujeito não mais competente para a política, para a vida social, para o trabalho, para o lazer e até mesmo para fazer escolhas conscientes.

Assim, diante dessas circunstâncias, nas últimas décadas um forte movimento científico e popular tem sido desenhado em favor da população idosa, na tentativa de desmistificar as verdades propagadas pelo imaginário social e reavaliar o papel do idoso frente à sociedade. Isso possibilita a construção de uma visão mais positiva a respeito do ser velho, em que se percebe que a vida não para com a chegada da velhice e que existe a possibilidade de vivenciar novas experiências.

Nesse contexto, a educação física, compreendida como um amplo campo de atuação profissional, progressivamente tem buscado apoiar-se em outras áreas do conhecimento para desenvolver práticas para a pessoa idosa que possam se desprender da visão extremamente biomédica que tradicionalmente tem estruturado as práticas de seus profissionais, como aquela construída pelo imaginário social a respeito do ser velho como a única verdadeira. Além disso, tem procurado se apropriar de outros pontos de vista na tentativa de desenvolver uma prática que liberte o sujeito de estigmas.

Muito embora estudos e pesquisas que possam corroborar a afirmativa da existência de um movimento de mudanças radicais na área da educação física para idosos sejam bastante recentes, a presença de indícios relativos à corrente progressivista das ciências da educação pode ser detectada na produção de alguns autores como: Okuma (1998); Velardi (2003); Silva Junior, et al (2006); Gerez et al (2010). Nessas obras, as escolhas político-sociais inerentes à atuação profissional são reveladas, ao mesmo tempo em que levantam uma bandeira em prol dos oprimidos e desprivilegiados socialmente. 
Esses estudos têm buscado evidenciar que, no contexto do envelhecimento, há necessidade de estruturação de uma educação física baseada na subjetividade e no saber dos sujeitos, onde a práxis pedagógica esteja atrelada às necessidades humanas, e que o agente educativo esteja em um processo constante de busca de conhecimento, da dialogicidade e da coerência entre a reflexão e a ação. E tudo isso exige do profissional de educação física uma retroalimentação do já sabido, o desvelamento de verdades absolutas, de ideologias propagadas tanto pela vida cotidiana como pelo mundo científico.

Significa dizer que uma proposta de educação física para idosos necessita superar o modelo biomédico e apoiar-se numa concepção em que as necessidades humanas, bem como o mundo vivido pelos idosos, sejam problematizados.

As necessidades humanas florescerão do mundo da vida que é formado no contexto das ações e situações que fornecerá subsídio de investigação dos temas a serem trabalhados no decorrer do processo educativo. Neste tipo de proposta pedagógica, o idoso é levado a refletir sobre os benefícios das atividades físicas para a sua saúde e a questionar-se: Quais os resultados esperados com a realização de determinada atividade? Quais os procedimentos necessários para sua realização? Quanto fazer de atividade física para obter os resultados desejados? Além de buscar estabelecer um elo entre a vida cotidiana e a prática da atividade física para que, munido dos conhecimentos necessários, possa elevar seu nível de consciência que o conduzirá a uma visão mais positiva sobre a velhice, e sobre a própria atividade física, podendo assim escolher entre fazer ou não atividade física (GEREZ, 2006).

É neste sentido que a estruturação de programas de educação física para idosa implica no desenvolvimento de uma práxis social dialógica, para que através do diálogo crítico a respeito das atividades físicas e do mundo vivido os idosos sejam desafiados a assumir-se enquanto seres epistemologicamente curiosos diante dos fenômenos 
que compõem a realidade circundante. No entanto, é mister enfatizar que a ação dialógica não deve ser compreendida como um simples ato conversacional entre o "eu" e o "tu". É necessária a compreensão de que o diálogo é um ato humano de ação/reflexão. Por esse motivo, "não pode reduzir-se a um ato de depositar idéias de um sujeito no outro, nem tão pouco tornar-se simples troca de idéias a serem consumidas pelos permutantes" (FREIRE, 1983, p. 79).

Desse modo, no contexto da educação física para idosos é importante que se assuma a interlocução, o ato comunicante, coparticipativo, a troca de saberes e a retroalimentação do já sabido como ponto de partida para superação da consciência ingênua, admitindo que o diálogo só é possível mediante o respeito à subjetividade e aos saberes dos sujeitos, o que favorece a conscientização humana e possibilita a construção da autonomia de homens e mulheres.

Nesta proposta educacional de interlocução e de "ensinar a pensar certo" a autonomia deixa de ser entendida como sinônimo de independência física e passa a ser compreendida como a experiência da liberdade, um processo pelo qual os indivíduos aprendem a ser sujeitos fazedores de cultura, criadores de sua própria história, que não se limita a uma única possibilidade. E isso, exigirá do profissional de educação física a coerência entre o discurso teórico e a prática.

Por esse motivo, os ganhos em aptidão física não poderão ser considerados como os únicos objetivos a serem atingidos, e a prática da atividade física não poderá ser reduzida à, simples realização, mas passará a ser um caminho para que os idosos possam conhecer e aprender sobre as suas limitações e potencialidades, facilitando o seu engajamento em tais práticas e ajudando-os em seu processo de desenvolvimento também em outras dimensões de sua vida.

A partir destas reflexões e por intermédio de uma proposta problematizadora, as discussões que se colocam neste ensaio visam avançar por um caminho que possa auxiliar na compreensão da pedagogia freireana, especificamente a respeito das categorias Diálogo e Autonomia que aqui serão analisadas, assim como na 
construção de uma educação física para idosos com viés crítico emancipatório, que seja capaz de colaborar para a inserção social de indivíduos historicamente oprimidos.

\section{0 dIÁLOGO FAVORECE A CONSCIENTIZAÇÃO HUMANA E POSSIBILITA A CONSTRUÇÃO DA AUTONOMIA DE HOMENS E MULHERES}

$\mathrm{Na}$ teoria do conhecimento postulada por Freire a categoria diálogo assume uma função essencial para o processo de construção do conhecimento. Entende Freire que é na relação dialógica entre os sujeitos e o objeto cognoscível que a construção do conhecimento floresce. Para ele, o conhecimento é uma construção coletiva, mediada dialogicamente, que deve articular dialeticamente a experiência da vida cotidiana com a sistematização rigorosa e crítica (FREIRE, 1983).

Desse modo, a palavra verdadeira adquire a responsabilidade de dizer o mundo e fazer o mundo, pois é por meio dela que a práxis social se compromete com a humanização de homens e mulheres. Pois, no entendimento de Freire (1993), somente o pensar verdadeiro é capaz de levar os sujeitos a construir sua própria história como ser histórico, levando-os a reconhecer e transformar criticamente os condicionamentos que estão inseridos na realidade. Assim o diálogo se constitui como um caminho, no qual os sujeitos estão em permanente movimento de construção e reconstrução.

Por essa razão, para a epistemologia freireana o diálogo não pode reduzir-se à simples troca de idéias entre sujeitos do processo comunicativo. É preciso compreendê-lo como fenômeno da natureza humana que exige a dialogicidade entre a ação e a reflexão, e provoca "[...] o encontro entre os homens, mediatizados pelo mundo para pronunciá-lo, não se esgotando, portanto, na relação eu-tu" (FREIRE, 1987, p.93). Mas adentrando as relações dos sujeitos com o mundo e a natureza, os quais armados do pensar verdadeiro possam transformar a realidade circundante. 
Compreende Freire (1993, p. 77), que "[...] não há palavra verdadeira que não seja práxis. Daí que dizer a palavra verdadeira seja transformar o mundo". Portanto, a condição necessária para a conscientização está assentada no diálogo. Uma vez que é mediante a intercomunicação, a troca de saberes que os conhecimentos mitificados, ingênuos são superados.

Tendo em vista o exposto, é possível sustentar que Freire desafia os educadores a serem inventores e reinventores de todos os meios que possibilitem a problematização do objeto, ou da realidade a ser descoberta e apreendida pelos sujeitos do processo educativo, reconhecendo estes como sujeitos do conhecimento. Incita os educadores à criação e recriação contínua da educação, por meio do diálogo, legitimado numa práxis libertadora.

Esse desafio implica na estruturação de metodologias coerentes com a educação libertadora. Ou seja, essencialmente dialógicas e, por extensão, conscientizadoras, que proporcionem aos sujeitos do processo educativo a apreensão do objeto cognoscível, e a tomada de consciência dos indivíduos em torno do mesmo (FREIRE, 1980).

No contexto da educação física para pessoa idosa é importante que o profissional de educação física assuma o processo educativo como um ato criador, crítico e o diálogo como elemento facilitador do conhecimento. É vital que no decorrer de sua práxis pedagógica sua ação dialética se transforme em testemunho prático de suas convicções político - filosóficas, e que sua práxis pedagógica possa conspirar contra o saber estático, contra a dominação do pensar, contra a reprodução dos gestos padronizados e se oriente por uma "concepção" que almeje a autonomia do 'ser velho'.

Essa educação física possível de realização só será realidade no momento em que seus profissionais desenvolverem atividades educativas ancoradas no diálogo crítico e criativo. Crítico, no sentido de ampliar o significado do movimento padronizado para movimento mais significativo, mais dialógico e exploratório, adquirindo novos valores para quem pratica. Criativo, enquanto capaz de produzir um novo homem, com uma visão de mundo que impulsione a vida 
autônoma. Que tenha a livre expressividade das vivências subjetivas com relação à vida em sociedade e à prática da atividade física.

No entanto, conforme já apontado,

A perspectiva educacional que pode ser coerente com a busca da autonomia é aquela que atribui ao educador a função de instaurar o rigor do método, em função de despertar a curiosidade, aquela que estimula a busca constante do conhecimento (VELARDI, 2003, p. 53).

Deste modo, uma proposta educacional que objetiva educar para a autonomia, implica no desenvolvimento de estratégias educacionais que levem os agentes do processo educativo a ver e compreender a realidade, expressar a realidade, expressar-se, numa contribuição para que os sujeitos tornem-se capazes de criar e transformar a realidade, em comunhão com seus semelhantes (NIDELCOFF, 1987; FREIRE, 1997).

Cabe elucidar, nesse momento, que na epistemologia freireana a categoria autonomia assume um lugar de destaque. Compreende Freire (1996) que, por sermos seres de cultura, somos necessariamente dependentes. Desta forma, a autonomia não se constrói sozinha ainda que, por vocação, os homens e as mulheres sejam capazes de apreender as coisas do mundo. E, por esse motivo, não há ignorância ou sabedoria absoluta. Em todas as nossas relações sociais, sejam elas com finalidades educacionais ou não, estamos em um constante processo de aprendizagem, mas isso não se dá de forma isolada, há necessidade de interação social para que os sujeitos cognoscentes captem a essência da realidade, e possam vir a ser um elemento de mudança na realidade na qual estão inseridos. Para tanto, deve haver por parte de quem educa uma finalidade em seu fazer educacional que leve ao estabelecimento de tais relações. Um processo de ensino-aprendizagem que se fundamente numa visão de sujeito como ser histórico que se realiza no tempo e seja capaz de criar e transformar a realidade, em parceria com seus semelhantes, apoiado no diálogo crítico que oportunize a reflexão de situações existenciais (FREIRE, 1978). 
Assim, em Freire, autonomia é um processo de decisão e humanização que os sujeitos vão construindo de acordo com os movimentos da sociedade, em decorrência de várias, inúmeras decisões que vão tomando ao longo da vida. Portanto, ninguém é primeiro autônomo para em seguida decidir. A autonomia vai se construindo mediante as experiências de decidir tomadas ao longo de sua existência (FREIRE, 1996). Logo, ninguém é dono da autonomia de ninguém, assim como ninguém é dono de sua própria autonomia. A autonomia se constrói mediante um processo de coerência e ética.

Desta forma, há uma grande necessidade de reflexão sobre o sentido dado ao termo "autonomia" na área da saúde, uma vez que inúmeros estudos têm demonstrado certa incoerência no significado atribuído a esse conceito. Como o estudo realizado por Silva Junior et al (2006), que concluiu haver na área da saúde uma tendência a aproximar os termos autonomia e independência, como se um fosse sinônimo do outro, o que acaba por distanciar a palavra autonomia de seu verdadeiro significado.

Segundo Farinatti (2000), no caso do envelhecimento alguns programas consideram importante associar atividade física e autonomia do indivíduo. No entanto, destaca o autor, quase sempre a palavra autonomia está ligada à independência, desconsiderando as outras dimensões da vida.

Matsuo (2007) ressalta que independência física é de extrema relevância. No entanto, no caso dos idosos cuja limitação física por sua vez se faz presente, a intervenção do profissional de saúde deve enfatizar aspectos que desenvolvam suas potencialidades, uma vez que o desenvolvimento não se encerra com a chegada da velhice. Nos escritos de Nerí (2004), encontramos explícito para que o sujeito tenha um envelhecimento bem sucedido é necessário, além da independência, a manutenção da autonomia, apontando a educação como elemento essencial para esse processo, por favorecer o auto-conhecimento, a auto-realização, assim como o desenvolvimento psicológico dos idosos, uma vez que o ser velho, assim como os demais sujeitos, encontra-se em pleno processo de 
desenvolvimento. Neste sentido, pode-se questionar: Como avançar no conhecimento na área da educação física se é exigido do sujeito apenas a repetição dos movimentos? Como conhecer mais a educação física se não há provocação à curiosidade, requisito necessário para a construção do conhecimento? Como chegar à autonomia se tudo já foi pré-determinado?

É sabido que a ação do conhecer que sustenta a educação física problematizadora deve ser compreendida como uma vertente educacional que recusa qualquer ato de dominação, mas que não ignora o debate e o conflito. Sendo assim, há de se pensar em uma proposta educacional que possibilite a participação efetiva do sujeito no processo de aprendizagem, que contribua para o desenvolvimento das potencialidades humanas e favoreça o pensar sobre si e o mundo (PEREIRA, 2003).

Para isso, a função do profissional da educação física é comprometer-se com uma prática educativa que não se reduza à transmissão de conhecimentos acerca de aspectos meramente fisiológicos ou biológicos do corpo humano, mas que possibilite a criatividade, autonomia e a cooperação entre os agentes do processo educativo (MATSUO, 2007).

Desta forma, o profissional de educação física deve oferecer à comunidade atendida uma educação rearranjada, refletida e integrada, possibilitando ao sujeito, no espaço cultural, político e social de que faz parte, se desenvolver junto com a sociedade e que este desenvolvimento social seja acompanhado pela transformação social, uma vez que,

A partir das relações do homem com a realidade, resultantes de estar com ela e de estar nela, pelos atos de criação, recriação e decisão, vai ele dinamizando o seu mundo. Vai dominando a realidade. Vai humanizando-a. Vai acrescentando a ela algo de que ele mesmo é o fazedor. Vai temporalizando os espaços geográficos (FREIRE, 1987, p. 43). 
Mas como trabalhar de forma problematizadora na área da educação física? Para esta pergunta, não existem respostas precisas, pelo fato da não existência de modelos prontos e acabados que possam ser indicados, o que temos são apenas conjecturas que podem indicar caminhos que necessariamente terão que ser constantemente refeitos, pois nunca deverão ser iguais (SIEBERT, 1991).

Neste sentido, como profissionais da educação física estamos cientes de que enquanto a educação física não se preocupar em relacionar às atividades físicas a vida cotidiana dos sujeitos, enquanto não questionar a validade dos conteúdos universais como os exercícios padronizados e o esporte institucionalizado a perspectiva da educação problematizadora, que objetiva a criatividade, a autonomia e a capacidade de cooperação não poderá ser alcançada.

Sabemos que não é raro na área da educação física observar educadores escondendo-se em aulas que se constituem em verdadeiros rituais a serem seguidos, desenvolvidas através de uma educação diretivista, para não revelarem o medo que têm de problematizar e dialogar sobre as atividades propostas. Para tal, justificam que "problematizar" e "dialogar" são perdas de tempo, fazendo adormecer a sua capacidade crítica e, consequentemente, a do educando. No entanto, "o diálogo e a problematização não adormecem a ninguém. Conscientizam" (FREIRE, 1996, p. 55).

Desse modo, a educação física problematizadora deve caminhar em sentido contrário ao imobilismo do pensamento, à reprodução do movimento e à disciplina do corpo. Deve preocupar-se em refletir sobre o movimento humano de forma dinâmica e contextualizada.

Porém, não estamos aqui afirmando que uma proposta de educação física problematizadora é alcançada mediante alternativas reformistas, ou com mudanças metodológicas. E, sim, buscando provocar reflexões que levem os profissionais da educação física a perceberem que a educação problematizadora deve orientar-se a partir de mudanças estruturais profundas em relação aos objetivos que se pretende com determinada atividade, com o planejamento das atividades e a coerência entre ação e a reflexão, que deve ser 
iniciada pela própria postura do educador diante da comunidade de interferência, uma vez que no entendimento de Prado (1993, p.109):

\begin{abstract}
Mudar o enfoque educacional não é simplesmente mudar o método ou a técnica, não é substituir a diretividade pelo espontaneísmo. Essa mudança é mais profunda, envolve mudar concepções e valores e, conseqüentemente, é o efeito dessa mudança que possibilita a criação e a re-criação do papel do professor calçado no conhecimento.
\end{abstract}

Neste viés é preciso que o planejamento, a organização, a metodologia, a estruturação e sistematização das atividades físicas sejam efetivamente concebidas numa prática libertadora, que tenha como eixo central do processo a aprendizagem dos sujeitos cognoscentes e não a apenas execução das atividades físicas em si.

Um dos pressupostos da educação problematizadora AÇÃO/ REFLEXÃO vem sendo vivenciado no contexto educacional do Projeto Sênior para a Vida Ativa implantado há nove anos na Universidade São Judas Tadeu localizada na cidade de São Paulo. Seus educadores, em ações conjuntas, têm buscado desenvolver uma educação física com caráter emancipatório.

Os profissionais que atuam no projeto, apoiados na epistemologia freireana têm procurado relacionar a prática da atividade física à vida cotidiana dos idosos. O que se almeja no projeto, através do diálogo, é problematizar as atividades físicas e relacioná-las com a realidade na qual os idosos estão inseridos para que, munidos dos conhecimentos sobre as atividades físicas e seus benefícios para sua vida, os idosos possam compreendê-las e transformá-las.

O diálogo verdadeiro e problematizador tem sido utilizado em todas as etapas da aula conceitos, procedimentos, realização. E isso independe do tema ou conteúdo que se pretende problematizar, porque segundo Freire (1993, p.53) "[...] tudo pode ser problematizado" por essa razão, as aulas do programa são estruturadas em aulas práticas-teóricas, nas quais os conhecimentos são construídos por meio das ações que promovem o desenvolvimento das unidades temáticas e são relacionados os diversos sistemas 
orgânicos (Cardiorrespiratório, Nervoso, Articular e Muscular), sobre os quais se analisa o processo de envelhecimento e como estimulálo adequadamente através da atividade física. Além disso, paralelamente ao ensino dos conteúdos relacionados à atividade física, os idosos são estimulados a refletirem sobre e a discutirem a própria realidade, ou seja, a pensarem sobre o que é envelhecer, permitindo-lhes rever os seus conceitos para construção de uma visão mais positiva da velhice.

Nesse contexto, as questões conceituais são trabalhadas através da leitura, do diálogo, da problematização e da reflexão, o que permite a construção de novos conhecimentos sobre atividade física e o envelhecimento, considerados necessários para favorecer escolhas livres e conscientes, assim como possibilitar o desenvolvimento de um pensamento crítico e reflexivo pelos idosos frente aos problemas que possam surgir no seu cotidiano.

Neste sentido, há um processo de capacitação do idoso para gerenciamento da atividade física e da sua própria vida, uma vez que são oferecidas condições para que identifiquem seus limites e potencialidades, permitindo a construção de uma nova visão sobre o fazer atividade física, para que não fiquem na eterna dependência das orientações advindas de um profissional.

Desta forma, as atividades físicas são utilizadas como meio para construção de diálogos sobre o processo de envelhecimento, e reflexão crítica sobre si mesmo, sua posição no mundo e a própria condição do ser velho, com o intuito de desmistificar as verdades propagadas pelo imaginário social e reavaliar o papel do idoso frente à sociedade.

De acordo com Freire (1995), este tipo de educação leva a uma posição de inquietude diante dos fatos sociais, tornando-os sujeitos investigadores e, assim, agregando em sua personalidade uma característica crítica, garantindo uma posição de poder administrar as escolhas de sua vida.

Além dessa visão freireana, Sen (2000) se coloca a favor de uma proposta educacional que tem como premissa a capacitação 
comunitária para reconhecimento de suas necessidades e tomadas de decisões, clarificando que a educação para a autonomia é o caminho que leva os sujeitos à reflexão individual e coletiva sobre tudo o que fazem. O que acarreta um impacto positivo no desenvolvimento social.

Sendo assim, o projeto supracitado situa-se como uma referência importante para enfatizar a proposição que a educação física para a pessoa idosa seja voltada à formação para o exercício da cidadania e, consequentemente da autonomia, pois os profissionais que atuam no projeto no decorrer de sua práxis pedagógica têm buscado inúmeras estratégias para promover a participação efetiva do grupo de idosos na construção do próprio conhecimento. Para Freire (1997), a organização sistemática das intenções educacionais é o passo inicial para as ações pedagógicas que objetivam a construção da cidadania e da autonomia.

Estes professores com tal ação educativa estão dizendo que desenvolver uma educação com viés problematizador/emancipatório não se restringe à mudança de metodologias ou de adoção de procedimentos progressivistas. Atuar com base em uma educação libertadora exige assumir conflitos e perceber que não é simplesmente no campo das idéias que se travam a frentes de lutas, mas também na práxis humana, o que exige o exercício permanente da reflexão e da ação. Pois a "[...] educação como prática da liberdade, ao contrário daquela que é prática da dominação, implica a negação do homem abstrato, isolado, solto, desligado do mundo como uma realidade ausente dos homens" (FREIRE, 1987, p.70).

Essa experiência dialógica-problematizadora nos leva a perceber que, para dialogar, não basta falar no diálogo é preciso vivenciá-lo numa relação democrática, horizontal, comprometida, interativa, crítica, transformadora, amorosa e esperançosa.

Portanto, as categorias freireanas diálogo e autonomia não são recursos didáticos, técnicas ou métodos pedagógicos. Mas são fundamentos de uma filosofia do conhecimento que se apoia num humanismo militante compromissado com a libertação de homens e mulheres. 


\section{ConsideraÇões Finals}

Diante das reflexões fomentadas no decorrer deste estudo seriamos incoerentes com o nosso propósito se chegássemos a qualquer tipo de conclusão, uma vez que não temos respostas prontas, acabadas para indicar como referencial para que os profissionais de educação física procedam diante da educação libertadora. Ao contrário, o que temos no intervalo dessa discussão é uma infinidade de perguntas que ainda não foram respondidas.

Estamos cientes de que não existe um modelo para seguir nesta concepção educativa. O que existe é uma teoria do conhecimento que proporciona aos educadores alguns pressupostos que deverão ser recriados para que sejam adequados ao grupo social em que serão utilizados. Contudo, sabe-se que ser coerente com a proposta educacional freireana exige a sua reinvenção.

Acredita-se, portanto pelas reflexões aqui suscitadas e pela experiência em educação física para a pessoa idosa descrita, que mudanças mais concretas em relação às propostas de educação física para idosos certamente irão acontecer, de fato, quando os profissionais dessa área utilizarem a dialogicidade e o ensino problematizador para contribuírem para a construção da autonomia do sujeito idoso, acreditando que ele é um ser curioso e que almeja aprender. 
The practice of physical education for elderly anchored in freire's pedagogy: reflections on a problem-dialogic experience

Abstract: Paulo Freire's pedagogic thinking (Freirian) has largely favored the improvement of both formal and informal educational practice. It has also contributed to spread critical worldview readings in which analytical categories educators have searched relief for their concerns. Hence, this paper starts from Paulo Freire's legacy in order to build a critical reflection about his categories of dialog and autonomy, as well as to start a conversation about senior physical education practice anchored in the Paulo Freire's pedagogy theory. It is based on a dialogicalproblematizing experience.

Keywords: Physical Education. Aged. Personal autonomy. La práctica de la educación física para mayores
anclado en la pedagogía de freire: reflexiones
sobre una experiencia de problemas dialogicos
Resumen: El pensamiento pedagógico de Paulo Freire
ha posibilitado la ampliación de practicas educativas
formales e informales, además de contribuir con la
generalización de lecturas críticas del mundo, ya que
en sus categorías de análisis los educadores buscan
respuestas a sus inquietudes. Así, y partiendo de la
obra de Freire, el objetivo del presente trabajo es
reflexionar críticamente acerca de las categorías
dialogo y autonomía, y asimismo iniciar discusiones
sobre la práctica de la educación física para la gente
mayor, anclada en los supuestos metodológicos de la
pedagogía de Freire. Para tanto reflexionaremos
acerca de una experiencia dialógica y
problematizadora.

Palabras clave: Educación Física. Anciano. Autonomía personal. 


\section{REFERÊNCIAS}

FARINATTI, P. T. V. A autonomia referenciada à saúde: modelos e definições. Motus Corporis, Rio de Janeiro, v.7, n. 1, p. 9-45, jan/mar., 2000.

FREIRE, P. Ação cultural para a liberdade. 3. ed. Rio de Janeiro: Paz e Terra, 1978.

Conscientização: teoria e prática da libertação. Uma introdução ao pensamento de Paulo Freire. 3. ed. São Paulo: Moraes, 1980.

Educação e Mudança. 6.ed. São Paulo: Paz e Terra, 1983.

Educação como prática da liberdade. 18. ed. São Paulo: Paz e Terra, 1987.

Política e educação. São Paulo: Cortez Editora, 1993.

À Sombra desta Mangueira. São Paulo: Olho D'Água, 1995.

Pedagogia da Autonomia. 37. ed. São Paulo: Paz e Terra, 1996.

Pedagogia da Esperança: um encontro com a pedagogia do oprimido. Rio de Janeiro: Paz e Terra, 1997.

GEREZ, A. G. A prática pedagógica em educação física para idosos e a educação em saúde: Um olhar sobre o Projeto Sênior para a vida ativa - USJT. 2006. 455 f. Dissertação de (Mestrado) - Educação Física. Departamento de Educação Física - USJT, São Paulo, 2006.

GEREZ, A. G; et al. M. Educação física e envelhecimento: uma reflexão sobre a necessidade de novos olhares e práticas. Motriz de Rio Claro, São Paulo, v. 16 n. 2 p. 485-489, abr./jun., 2010.

MATSUO, R. F. O sentido de saúde em idosos do projeto sênior para a vida ativa da USJT. 2007. 98 f. Dissertação de (Mestrado) - Educação Física. Departamento de Educação Física - USJT, São Paulo 2007.

NERI, A. L. Velhice bem-sucedida: aspectos afetivos e cognitivos. Revista PsicoUSF, lataiba, v. 9, n. 1, p. 109-110, set/out., 2004.

NIDELCOFF, M. T. A escola e a compreensão da realidade. 15. ed. São Paulo: Brasiliense, 1987.

OKUMA, S. S. O idoso e a atividade física: fundamentos e pesquisa. Campinas: Papirus, 1998.

PEREIRA, A. L. F. As tendências pedagógicas e a prática educativa na ciência da saúde. In: Cadernos de Saúde pública, Rio de Janeiro. v.19, n. 5, p. 1527-1534, set./out., 2003. 
PRADO, M.E.B.B. Logo no Curso de Magistério: O Conflito entre Abordagens Educacionais. In: Valente, J. A. (org.) Computadores e Conhecimento: Repensando a Educação. Campinas: Gráfica da Unicamp,1993.

SIEBERT, R. S. S. Dominação e autoritarismo na prática pedagógica da educação física e as possibilidades de superação. Contexto \& educação, ljuí, v.6, n. 21, p.66-77, jan/mar., 1991.

SILVA JÚNIOR, A. P. et al. Autonomia e Educação Física: uma perspectiva à luz do ideário da Promoção da Saúde. Conexões, Campinas, v.4, n.1, p. 15-33, jun/ mar., 2006.

SEN, A. A liberdade individual como compromisso social. In: SEN, A. Desenvolvimento com liberdade. São Paulo: Companhia das Letras, 2000.

VELARDI, M. Pesquisa-ação em educação física para idosos. 2003. $188 \mathrm{f}$. Tese de (Doutorado) - Educação Física - Faculdade de Educação Física, Unicamp, Campinas, 2003.

Endereço para correspondência:

Rua: Frei Gaspar, 546, apt 04,

Mooca, São Paulo/São Paulo

CEP: 03164100 
